\title{
Pilot Study on the Effect of Grounding on Delayed-Onset Muscle Soreness
}

\author{
Dick Brown, Ph.D., Gaétan Chevalier, Ph.D., ${ }^{1}$ and Michael Hill, B.S.
}

\begin{abstract}
Objectives: The purpose of this pilot study was to determine whether there are markers that can be used to study the effects of grounding on delayed-onset muscle soreness (DOMS).

Design and subjects: Eight (8) healthy subjects were exposed to an eccentric exercise that caused DOMS in gastrocnemius muscles of both legs. Four (4) subjects were grounded with electrode patches and patented conductive sheets connected to the earth. Four (4) control subjects were treated identically, except that the grounding systems were not connected to the earth.

Outcome measures: Complete blood counts, blood chemistry, enzyme chemistry, serum and saliva cortisols, magnetic resonance imaging and spectroscopy and pain levels were taken at the same time of day before the eccentric exercise and 24, 48, and 72 hours afterwards. Parameters consistently differing by $10 \%$ or more, normalized to baseline, were considered worthy of further study.

Results: Parameters that differed by these criteria included white blood cell counts, bilirubin, creatine kinase, phosphocreatine/inorganic phosphate ratios, glycerolphosphorylcholine, phosphorylcholine, the visual analogue pain scale, and pressure measurements on the right gastrocnemius.

Conclusions: In a pilot study, grounding the body to the earth alters measures of immune system activity and pain. Since this is the first intervention that appears to speed recovery from DOMS, the pilot provides a basis for a larger study.
\end{abstract}

\section{Introduction}

$\mathbf{F}$ OR MOST OF OUR EVOLUTIONARY HISTORY, humans have had continuous contact with the earth. It is only recently that substances such as asphalt, wood, rugs, and plastics have separated us from this contact. Research articles have documented the potential benefits of being grounded to the earth. These articles have reported improved sleep, normalization of cortisol circadian rhythm, reduced stress, ${ }^{1}$ and normalization of physiologic and electrophysiologic parameters. ${ }^{2,3}$ A comprehensive review of the potential benefits of grounding has been published recently. ${ }^{4}$ A patent has been awarded for a process called "grounding" that connects a conductive bed sheet to the earth, allowing a person to sleep connected to the earth (patent \#6,683,779; personal body grounding system; January 27, 2004).

The purpose of this pilot study was to see whether there were markers that might differentiate between subjects who had undergone a bout of eccentric exercise resulting in delayed-onset muscle soreness (DOMS) and acute inflam- mation and were then "grounded" by sleeping on the patented sheets as opposed to those who had undergone the same process but slept on sham sheets and were not "grounded." If markers were able to differentiate these groups, these markers could be studied in greater detail with a larger subject base in the future.

\section{Materials and Methods}

\section{Subjects}

Eight (8) men were randomly assigned to a grounded $(\mathrm{GRD})$ or ungrounded $(\mathrm{UNG})$ group $(\mathrm{GRD}=4 ; \mathrm{UNG}=4)$. Because of extensive controls and the purpose of the study, only 8 subjects were selected. All subjects were between the ages of 20 and 23 with a body weight between 150 and 175 pounds and a body mass index within the healthy range (18.5-24.9). All subjects were required to complete a medical history to ensure eligibility and that they were free of injuries or disease. All subjects were informed of the

\footnotetext{
${ }^{1}$ Human Physiology Department, University of Oregon, Eugene, Eugene, OR.

${ }^{2}$ Developmental and Cell Biology Department, University of California at Irvine, Irvine, CA and Earth FX Inc., Palm Springs, CA.
} 
purpose/possible risks involved in the investigation and were required to read and sign an informed consent prior to participation. The study was approved by the Human Subjects Committee at the University of Oregon.

In order to control variables, only 1 subject was studied each week, Sunday afternoon through Thursday evening. All markers were obtained at exactly the same time of day (see Table 1 for a list of all 48 markers). All subjects stayed in the same motel room for the duration of the study, leaving only for tests to which they were driven. They all were provided with equal amounts of identical food. They ate at 8:00 $\mathrm{AM}, 12: 00 \mathrm{PM}$, and 6:00 PM. They were required to be in bed at 9:30 PM and arise at 7:00 AM. At 5:40 PM on Monday through Wednesday, subjects were grounded to the earth via conductive patches placed on their gastrocnemius and on the bottom of both feet. They kept the patches on when they went to bed. With the exceptions of bathroom visits and eating, they were required to stay on the grounded sheet. The grounded subjects used grounded patches and sheets, while the ungrounded subjects used patches and sheets whose connections had been modified to prevent a ground connection. This was a double-blind study, and neither the subjects nor the investigator knew the grouping.

Table 1. List of All 48 Markers

\begin{tabular}{|c|c|c|}
\hline System & Parameter name & Abbreviation \\
\hline Immune blood cell & $\begin{array}{l}\text { White blood cells } \\
\text { Neutrophils } \\
\text { Lymphocytes } \\
\text { Monocytes } \\
\text { Eosinophils } \\
\text { Basophils }\end{array}$ & $\begin{array}{l}\text { WBC } \\
\text { Neut } \\
\text { Lymph } \\
\text { Mono } \\
\text { EOS } \\
\text { BASO }\end{array}$ \\
\hline Red blood cells & $\begin{array}{l}\text { Red blood cells } \\
\text { Hemoglobin } \\
\text { Hematocrit } \\
\text { Mean corpuscular volume } \\
\text { Mean corpuscular hemoglobin } \\
\text { Mean corpuscular hemoglobin concentration } \\
\text { RBC distribution width } \\
\text { Platelets } \\
\text { Mean platelet volume }\end{array}$ & $\begin{array}{l}\text { RBC } \\
\text { HGB } \\
\text { HCT } \\
\text { MCV } \\
\text { MCH } \\
\text { MCHC } \\
\text { RDW } \\
\text { Plt } \\
\text { MPV }\end{array}$ \\
\hline Blood chemistry & $\begin{array}{l}\text { Sodium } \\
\text { Potassium } \\
\text { Chloride } \\
\text { Calcium } \\
\text { Carbon dioxide } \\
\text { Blood urea nitrogen } \\
\text { Creatinine } \\
\text { Glucose } \\
\text { Total protein } \\
\text { Albumin } \\
\text { Bilirubin }\end{array}$ & $\begin{array}{l}\mathrm{Na} \\
\mathrm{K} \\
\mathrm{Cl} \\
\mathrm{Ca} \\
\mathrm{CO}_{2} \\
\text { BUN } \\
\text { Creatn } \\
\text { GLU } \\
\text { Tlt Pro } \\
\text { Alb } \\
\text { BILIRUBIN }\end{array}$ \\
\hline Enzymes/hormones & $\begin{array}{l}\text { Creatine kinase } \\
\text { Alanine transaminase } \\
\text { Asparate transaminase } \\
\text { Alkaline phosphatase } \\
\text { Saliva cortisol } \\
\text { Serum cortisol } \\
\text { Interleukin } 6\end{array}$ & $\begin{array}{l}\text { CK } \\
\text { ALT } \\
\text { AST } \\
\text { Alk Phos } \\
\text { Slv Cort } \\
\text { Srm Cort } \\
\text { IL6 }\end{array}$ \\
\hline Magnetic resonances & $\begin{array}{l}\text { Magnetic resonance imaging (proton } \mathrm{T} 2 \text { relaxation time) } \\
\text { Alpha phosphate } \\
\text { Beta phosphate } \\
\text { Gamma phosphate } \\
\text { Phosphocreatine concentration } \\
\text { Inorganic phosphate } \\
\mathrm{Pi} / \mathrm{PCr} \text { ratio } \\
\mathrm{pH} \\
\text { Glycerophosphorylethanolamine } \\
\text { Phosphorylethanolamine } \\
\text { Glycerophosphorylcholine } \\
\text { Phosphorylcholine }\end{array}$ & $\begin{array}{l}\text { MRI } \\
\text { Alpha } \\
\text { Beta } \\
\text { Gamma } \\
\text { PCr } \\
\text { PI } \\
\text { Pi/PCr } \\
\text { pH } \\
\text { GPE } \\
\text { PE } \\
\text { GPC } \\
\text { PC }\end{array}$ \\
\hline Pain & $\begin{array}{l}\text { AM soreness scale } \\
\text { PM soreness scale } \\
\text { PM blood pressure cuff }\end{array}$ & $\begin{array}{l}\text { AM SC } \\
\text { PM SC } \\
\text { PM BPC }\end{array}$ \\
\hline
\end{tabular}




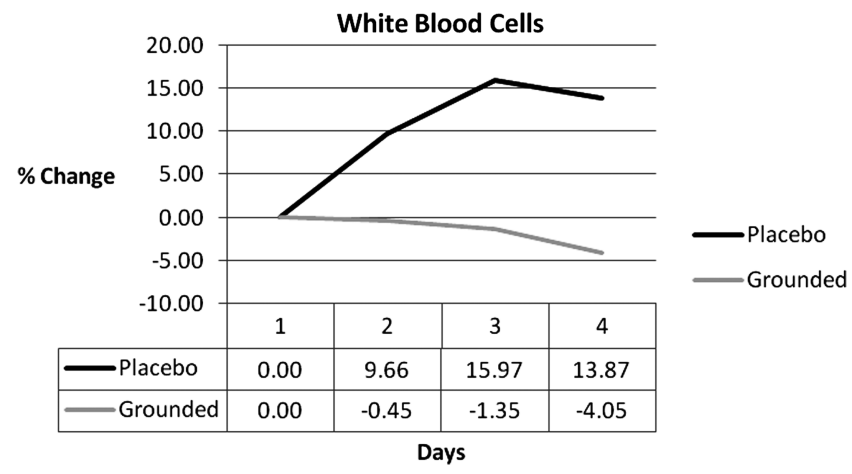

FIG. 1. White blood cells: pretest versus post-test comparisons for each group.

\section{Blood sampling}

Blood markers included a complete blood count, a blood chemistry, creatine kinase, aspartate transaminase, alanine transaminase, alkaline phosphatase, interleukin-6, and serum cortisol. All blood draws were done in the subject's motel room at 8:00 AM by a certified phlebotomist from Legacy Laboratories, Eugene, OR. Blood samples were analyzed by Legacy Laboratories.

\section{Magnetic resonance imaging and spectroscopy}

All magnetic resonance imaging and spectroscopy was completed each day at 9:00 AM at the Lewis Center for Neuroimaging on the campus of the University of Oregon at Eugene under the direction of Dr. Scott Frey. The sites were the right and left gastrocnemius muscles located in the middle of each gastrocnemius, 8 and $16 \mathrm{~cm}$ distal to the knee joint. The subjects were placed in the magnet, a Siemans Alegra 3 Tesla, on their backs with the coils on the selected sites.

\section{Saliva cortisol}

Saliva cortisol was collected each morning at 8:00 AM by the Legacy Laboratory certified phlebotomist and analyzed by Legacy Laboratories.

\section{Pain}

Pain was measured subjectively and objectively. The subjects completed the Visual Analogue Soreness Scale each day at 8:00 AM and 5:30 PM.

Also at 5:35 PM, the subjects were tested for pain by having a blood pressure cuff placed around their right gas-

Table 2. Percent Group Differences: White Blood Cells

\begin{tabular}{lcrcr}
\hline & Monday & Tuesday & Wednesday & Thursday \\
\hline White blood cells & 0.00 & $\mathbf{- 1 0 . 1 1}$ & $\mathbf{- 1 7 . 3 2}$ & $\mathbf{- 1 7 . 9 2}$ \\
Neutrophils & 0.00 & -8.13 & $\mathbf{- 1 2 . 9 7}$ & $\mathbf{- 1 1 . 4 5}$ \\
Lymphocytes & 0.00 & -3.08 & $\mathbf{- 1 2 . 7 0}$ & $-\mathbf{1 4 . 3 9}$ \\
Eosinophils & 0.00 & -3.23 & $\mathbf{- 1 6 . 5 9}$ & $-\mathbf{2 4 . 1 4}$ \\
Basophils & 0.00 & $\mathbf{3 1 . 5 2}$ & $\mathbf{2 9 . 7 0}$ & 2.42 \\
\hline
\end{tabular}

Bolding indicates differences $\geq 10 \%$.
Table 3. Percent Group Differences: Red Blood Cells

\begin{tabular}{lcccc}
\hline & Monday & Tuesday & Wednesday & Thursday \\
\hline Hemoglobin & 0.00 & -0.17 & -0.78 & -3.45 \\
Hematocrit & 0.00 & -0.21 & -1.87 & -4.12 \\
Mean corpuscular & 0.00 & -0.08 & -1.09 & -0.35 \\
$\quad$ volume & & & & \\
Mean platelet volume & 0.00 & -3.33 & -7.62 & -2.86 \\
\hline
\end{tabular}

trocnemius. It was slowly inflated until the subject requested that no more pressure be administered due to a feeling of acute discomfort.

\section{Delayed-onset muscle soreness protocol}

DOMS is a well-known result of excessive, unfamiliar, or intensive exercise movements. Muscle cell breakdown occurs along the Z-lines, which are the regions where tension developed within the muscle cell is conducted to the myofascial system, and by leakage across cell membranes. ${ }^{5-9}$ To date, there is no known treatment that reduces the time frame to recovery, but apparently massage and hydrotherapy ${ }^{6-8}$ and acupuncture $^{10}$ can reduce pain. This condition presents in 24-48 hours after the exercise and its duration can last well over 96 hours. $^{9,11}$ It produces acute inflammation in the muscle(s) affected. $5,6,10,11$

All subjects were tested Monday between 8:00 AM and 9:45 AM prior to any DOMS producing contractions. On Monday at 10:00 AM, eccentric toe raises were performed, which resulted in DOMS and acute inflammation.

The subjects completed two sets of 20 eccentric toe raises. They placed a barbell equal to one third of their body weight on their shoulders. They then placed the balls of their feet on a stable $2 \times 4$, making their toes approximately 2 inches higher than their heels. There was a spotter behind them at all times. On command, they rose up on their toes to a fully extended position and held that position for 10 seconds. At the end of 10 seconds, they lowered their heels to the floor. Upon touching the floor, they rose up to the fully extended position and held it again for 10 seconds. After 20 repetitions, they had a 2-minute rest and then repeated the 20-repetition procedure.

\section{Analysis}

Because the goal of the pilot study was to select markers for further study and because the number of subjects did not lend itself to normal statistical methods, another standard was chosen. The study goal might be met by selecting markers

Table 4. Percent Group Differences: Blood Chemistry

\begin{tabular}{lcrrr}
\hline & Monday & Tuesday & Wednesday & Thursday \\
\hline Chloride & 0.00 & -0.49 & -1.48 & -0.25 \\
Sodium & 0.00 & -2.20 & -3.10 & -2.01 \\
Carbon dioxide & 0.00 & -6.75 & -7.39 & -7.75 \\
Glucose & 0.00 & $-\mathbf{2 3 . 0 3}$ & -9.46 & $\mathbf{- 1 4 . 5 2}$ \\
Blood urea nitrogen & 0.00 & -0.38 & $\mathbf{- 1 5 . 2 9}$ & -3.58 \\
Bilirubin & 0.00 & $\mathbf{2 7 . 4 1}$ & $\mathbf{3 5 . 7 0}$ & $\mathbf{2 6 . 2 7}$ \\
Creatinine & 0.00 & -0.86 & -5.58 & -4.25 \\
\hline
\end{tabular}

Bolding indicates differences $\geq 10 \%$. 
Table 5. Percent Group Differences: ENZYMES AND HORMONES

\begin{tabular}{lcrrr}
\hline & Monday & Tuesday & Wednesday & Thursday \\
\hline $\begin{array}{l}\text { Creatine kinase } \\
\text { Alkaline }\end{array}$ & 0.00 & $-\mathbf{2 6 . 8 1}$ & $-\mathbf{2 0 . 7 4}$ & $\mathbf{- 8 6 . 5 2}$ \\
$\quad$ phosphatase & 0.00 & -5.23 & -7.70 & -5.71 \\
$\begin{array}{l}\text { Aspartate } \\
\quad \text { transaminase }\end{array}$ & 0.00 & 2.39 & $\mathbf{1 3 . 7 0}$ & $\mathbf{1 6 . 6 9}$ \\
$\begin{array}{l}\text { Interleukin 6 } \\
\text { Saliva cortisol }\end{array}$ & 0.00 & $\mathbf{2 7 . 7 0}$ & 4.71 & $\mathbf{- 1 2 . 8 1}$ \\
\hline
\end{tabular}

Bolding indicates differences $\geq 10 \%$.

that showed (1) a difference between GRD and UNG that was equal to or greater than $10 \%$ and (2) a consistent pattern of one group's results being always above or below the other group for all post-tests.

Total bilirubin is a good example of how the $10 \%$ threshold was determined. Genzyme Diagnostics (Genzyme Diagnostics P.E.I. Inc., Charlottetown, Prince Edward Island, Canada) reports that interferences from hemoglobin, lipemia, and ascorbic acid were evaluated for their total bilirubin method on a Hitachi analyzer using a significance criterion of $>10 \%$ variance from control. Furthermore, the same company presents results of precision studies showing precisions varying from $1.1 \%$ to $3.1 \%$ and the result from an accuracy study showing an accuracy of $5 \%$ based on the slope of the linear regression equation. Because attainment of the markers was timed precisely in order to eliminate circadian rhythms as a confounding factor and all other aspects of their lives were controlled, it was felt that using a criterion twice Genzyme's accuracy result would be conservative, in agreement with their own assessment that a significance criterion of $>10 \%$ variance was giving them reasonable results. Consequently, we felt that if the two standards listed above were met, these markers would be worthy of further consideration in a study with more subjects.

The $10 \%$ or greater difference was determined in the following manner:

1. Results for each day (Monday, Tuesday, Wednesday, and Thursday) were averaged for each group.

2. Percent differences for each day of each group were calculated with pretest (Monday) values as reference values using the formula: ((post-test/pretest) -1$)^{*} 100 \%$.

3. The difference between groups for each day was determined by subtracting the ungrounded group per- cent difference from the grounded group percent difference.

Example: Grounded group \% difference $=-7 \%$; Ungrounded group $\%$ difference $=9 \%$.

Percent difference between grounded and ungrounded groups $=-7 \%-9 \%=-16 \%$.

Using this method, the pretest difference within each group would be " $0 \%$ " and both groups would start at the same baseline on the graph (see Fig. 1 as an example for white blood cells).

\section{Results}

\section{Complete blood count: White blood cells}

Five (5) of six white blood cell markers showed a consistent pattern in which readings in one group were always above or below the other group. Eleven (11) readings reached the $\geq 10 \%$ difference between GRD and UNG (Table 2).

\section{Complete blood count: Red blood cells}

None of the red blood cell markers showed differences $\geq 10 \%$. However, four of nine markers showed a consistent pattern in that the grounded group was always below the ungrounded group (Table 3).

\section{Blood sampling: Blood chemistry}

Seven (7) of 11 markers showed a consistent pattern in which readings in one group were always above or below the other group. Six (6) readings reached the $\geq 10 \%$ difference (Table 4).

\section{Blood sampling: Enzymes and hormones}

In three of seven markers, one group was always above or below the other group. Nine (9) readings reached the $\geq 10 \%$ difference (Table 5).

\section{Magnetic resonance: Imaging and spectroscopy}

In 7 of 12 markers, one group was always above or below the other group. Seventeen (17) readings reached the $\geq 10 \%$ difference (Table 6).

\section{Pain evaluation}

In all markers, one group was always above or below the other group and readings reached the $\geq 10 \%$ difference (Table 7).

Table 6. Percent Group Differences: Magnetic Resonance Imaging (MRI) and Spectroscopy

\begin{tabular}{|c|c|c|c|c|}
\hline & Monday & Tuesday & Wednesday & Thursday \\
\hline Inorganic phosphate & 0.00 & -11.25 & $-\mathbf{1 7 . 7 9}$ & $-\mathbf{1 7 . 8 0}$ \\
\hline $\mathrm{Pi} / \mathrm{PCr}$ ratio & 0.00 & -13.44 & -19.71 & -16.22 \\
\hline $\mathrm{pH}$ & 0.00 & -0.22 & -0.22 & -0.24 \\
\hline Alpha phosphate & 0.00 & 7.70 & 5.31 & 1.21 \\
\hline Glycerophosphorylcholine & 0.00 & 40.73 & 42.44 & 67.66 \\
\hline Phosphorylcholine & 0.00 & 25.22 & 66.17 & 26.92 \\
\hline Glycerophosphorylethanolamine & 0.00 & -58.35 & 7.96 & 21.57 \\
\hline Phosphorylethanolamine & 0.00 & 9.98 & -25.47 & -14.41 \\
\hline MRI (proton T2 relaxation time) & 0.00 & 4.02 & 4.70 & 10.61 \\
\hline
\end{tabular}

Bolding indicates differences $\geq 10 \%$. 
Table 7. Percent Group Differences: Pain Evaluation

\begin{tabular}{lrrrr}
\hline & Monday & Tuesday & Wednesday & Thursday \\
\hline AM soreness scale & 0.00 & $\mathbf{- 9 5 . 0 8}$ & $\mathbf{- 1 7 9 . 2 1}$ & $\mathbf{- 1 0 1 . 1 9}$ \\
PM soreness scale & 0.00 & $-\mathbf{8 5 . 5 3}$ & $-\mathbf{8 3 . 2 8}$ & $-\mathbf{8 6 . 2 8}$ \\
PM blood pressure cuff & 0.00 & $\mathbf{2 6 . 8 0}$ & $\mathbf{2 9 . 1 8}$ & $\mathbf{3 1 . 9 2}$
\end{tabular}

Bolding indicates differences $\geq 10 \%$.

Table 8. Three-Day Comparison Summary

\begin{tabular}{lcc}
\hline Test area & Markers & $\begin{array}{c}\text { Consistent group differences } \\
\text { over 3-day }\end{array}$ \\
\hline White blood cells & 6 & 5 \\
Red blood cells & 9 & 5 \\
Blood chemistry & 11 & 7 \\
Enzymes/hormones & 7 & 3 \\
Magnetic resonance & 12 & 7 \\
Pain & 3 & 3 \\
Total & 48 & 30 \\
\hline
\end{tabular}

Table 9. Expected Versus Actual Crossings

\begin{tabular}{lcc}
\hline & Expected & Actual \\
\hline Never cross & 12 & 30 \\
Cross before day 3 & 12 & 11 \\
Cross before day 4 & 12 & 4 \\
Cross before day 3 and day 4 & 12 & 3 \\
\hline
\end{tabular}

\section{Discussion}

This pilot study examined the effects of being grounded on well-established markers of acute inflammation and other markers related to DOMS such as magnetic resonance imaging and pain markers. A total of 48 markers were considered and each was compared, over a 3-day post-test period, with the first day pretest. Table 8 compares 48 markers over 3 days. Of the potential 48 markers, 30 markers showed a consistent pattern of group differences in which one group was always above or below the other group. This meant that the lines on the graph never crossed, as seen in Figure 1. At random there should be 12 occasions where the lines never cross, 12 where they cross twice, 12 where they cross between day 2 and day 3, and 12 where they cross between day 3 and day 4 . In graphing these data, the lines never crossed on 30 occasions. Table 9 shows the number of times that crossing did or did not occur. The $\chi^{2}$ test for independence produces a figure smaller than 0.0000005 for these data, indicating that the probability of it happening by chance is very low. It would be reasonable to expect that an influencing factor, in this case grounding, might have had a role in producing the results.

The 48 markers each had three data points (total of 144) by which percentage differences between UNG and GRD could be compared. Table 10 shows the number of comparisons where differences were $\geq 10 \%$ and those that were $\geq 20 \%$. In 52 of 144 marker comparisons (36.1\%), there was at least a $10 \%$ difference and in 30 of those cases $(20.8 \%)$ the difference was at least $20 \%$. It is logical that (1) an influencing factor could be at work and (2) some markers merit further discussion. In each of the major test areas, except red blood cells, there was at least one marker that fulfilled both requirements for further investigation. These are presented in Table 11.

\section{White blood cells}

There are different types of white blood cells: neutrophils, lymphocytes, monocytes, eosinophils, and basophils. An increase in white blood cell production occurs when the immune system is called upon to defend the body against infectious disease, foreign materials, or damaged cells. ${ }^{12-16}$ In this study, while the white blood cells of UNG increased, the white blood cells of GRD decreased at 24, 48, and 72 hours postexercise; the differences between the two groups were $10 \%, 17 \%$, and $18 \%$.

Research has also shown that the white blood cell increase is from an increase in neutrophils. ${ }^{17-20}$ While both groups showed an increase in neutrophils at all post-tests, the GRD were always below UNG (Fig. 2). The differences were $8 \%$, $13 \%$, and $11 \%$. Other studies indicate that as neutrophils increase the lymphocytes decrease. ${ }^{21-23}$ GRD lymphocytes were always below UNG and below baseline (Fig. 3).

The normal inflammatory reaction is for the neutrophils to rapidly invade the damaged cells, ${ }^{12,24-26}$ where they initiate cleanup and ultimately help in the signaling of the repair process. ${ }^{12,27,28}$ One of their actions is to produce reactive oxygen species (ROS). ${ }^{25}$ In inflammation, ROS are also produced by an array of other molecules and via oxygen metabolism in the conversion of cellular energy, of which a significant amount is required during the inflammatory process. While ROS are important in tissue regeneration, it is possible for ROS to start chain reactions that damage normal cellular components. Enzymatic and endogenous antioxidants, as well as antioxidants from the diet, are required to limit a chain reaction. However, sometimes the antioxidants are overwhelmed by the quantity of ROS. ${ }^{29,30}$ Some studies conclude that ROS outcomes are attenuated by antioxidant

Table 10. Percent Differences Between Markers in “Ungrounded” and “Grounded” Subjects

\begin{tabular}{lcccc}
\hline Test area & Markers & Possible comparisons & Difference $\geq 10 \%$ & Difference $\geq 20 \%$ \\
\hline White blood cells & 6 & 18 & 12 & 3 \\
Red blood cells & 9 & 27 & 0 & 0 \\
Blood chemistry & 11 & 33 & 6 & 4 \\
Enzymes/hormones & 7 & 21 & 9 & 7 \\
Magnetic resonance & 12 & 36 & 17 & 8 \\
Pain & 3 & 9 & 53 & 9 \\
Total & 48 & 144 & 51 \\
\hline
\end{tabular}


Table 11. Consistent Differences Between GROUPS $\geq 10 \%$

\begin{tabular}{lrrr}
\hline & Day 1 vs & Day 1 vs & Day 1 vs \\
Marker & Day 2 & Day 3 & \multicolumn{1}{c}{ Day 4 } \\
\hline White blood cells & -10.11 & -17.32 & -17.92 \\
Bilirubin & 27.41 & 35.70 & 26.27 \\
Creatine kinase & -26.81 & -20.74 & -86.52 \\
Inorganic phosphate & -11.25 & -17.79 & -17.80 \\
Pi/PCr ratio & -13.44 & -19.71 & -16.22 \\
Glycerophosphorylcholine & 40.73 & 42.44 & 67.66 \\
Phosphorylcholine & 25.22 & 66.17 & 26.92 \\
AM soreness scale & -95.08 & -179.21 & -101.19 \\
PM soreness scale & -85.53 & -83.28 & -86.28 \\
PM blood pressure cuff & 26.80 & 29.18 & 45.36 \\
\hline
\end{tabular}

$\mathrm{Pi} / \mathrm{PCr}$, inorganic phosphate/phosphocreatine.

supplementation. ${ }^{31}$ Perhaps if there were more antioxidants available, not only might the original damage be resolved more quickly, but the damage to healthy tissue might be reduced and the recovery process might proceed more rapidly. In this event, fewer neutrophils may be required and this could be reflected by the lower number in the blood of the GRD subjects. Fewer neutrophils may also be beneficial because in cases of muscle damage, which induces acidosis and hypoxia, the normally short-lived neutrophils may play a role in prolonging inflammation. ${ }^{32}$ If issues were resolved more rapidly, there might also be a lower requirement for natural killer lymphocytes, which arrive at the relevant site soon after neutrophils and are another source of ROS. GRD had baseline levels of lymphocytes lower than UNG.

Even though the monocytes did not meet conditions 1 or 2 , they were interesting. Monocytes replenish resident macrophages and dendritic cells under normal conditions and move (after 8-12 hours) to sites of inflammation and divide into macrophages or dendritic cells. After 24 hours, the monocytes in the ungrounded group increased into the positive range while the grounded group stayed below pretest values (Fig. 4). Since monocytes were the only white blood cells to increase in the UNG group only, it is a reasonable assumption that they were responsible for a difference in response between the two groups (i.e., an increase inflammatory response for the control group and a decrease in inflammatory response for the grounded group).

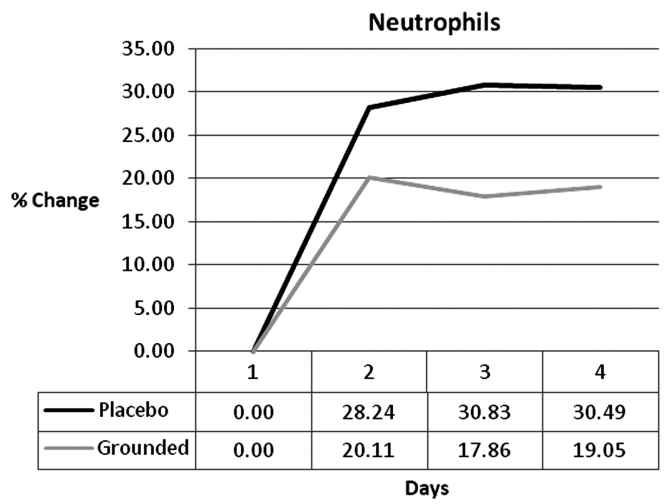

FIG. 2. Neutrophil differences.

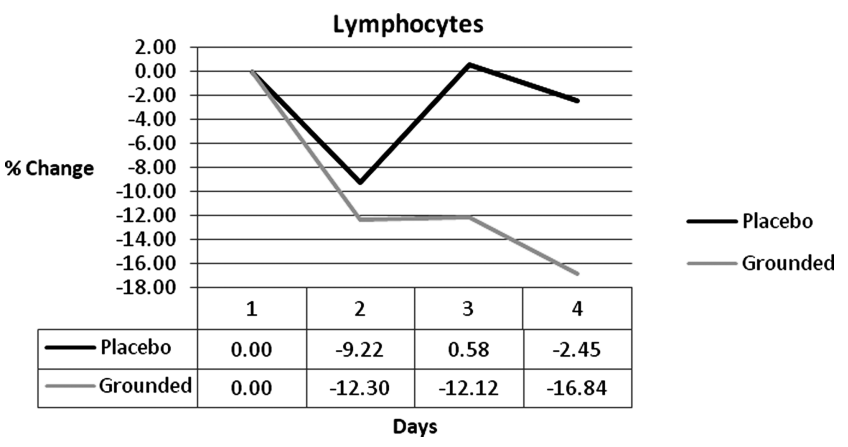

FIG. 3. Lymphocyte differences.

In addition to enzymatic, endogenous, and dietary antioxidants, bilirubin is an antioxidant that can help control free radicals. ${ }^{33-37}$ While both groups decreased blood bilirubin levels, the margin between the UNG and GRD subjects was large: $27 \%, 36 \%$, and $26 \%$ (Fig. 5). The damaged cells in the UNG subjects may have used bilirubin as a source of electrons. Perhaps the smaller decrease of bilirubin in GRD was due to an additional source of free electrons that could be accessed more easily and more quickly.

Three (3) markers support the idea that GRD may have had a more efficient resolution of damage: creatine kinase $(\mathrm{CK})$, inorganic phosphate/phosphocreatine ratios (Pi/PCr), and pain markers. $\mathrm{CK}$ has been accepted as a marker of muscular damage for a long period of time. ${ }^{30,38,39}$ UNG was always above the GRD group by $27 \%, 21 \%$, and $87 \%$ (Fig. 6). Magnetic resonance spectroscopy (MRS) showed a difference between $\mathrm{Pi} / \mathrm{PCr}$ of the two groups. $\mathrm{Pi} / \mathrm{PCr}$ ratios have been used to determine cellular damage and metabolic rate. ${ }^{40-43}$ $\mathrm{Pi}$ increases when phosphates are split from $\mathrm{PCr}$ in the conversion of energy. ${ }^{44}$ The results show that UNG consistently had higher levels of $\mathrm{Pi}$ and at the same time GRD had consistently higher levels of $\mathrm{PCr}$. The combination of reducing the $\mathrm{Pi}$ and increasing or maintaining the $\mathrm{PCr}$ has the effect of decreasing the $\mathrm{Pi} / \mathrm{PCr}$ ratio. This, in turn, indicates that the mitochondria are converting energy at a lower level, either because they are unable to metabolize faster or because there is no need for them to metabolize faster. The latter may be the case if homeostasis was closer to being achieved. The difference between the groups in the $\mathrm{Pi} / \mathrm{PCr}$ ratio was $13 \%$, $20 \%$, and $16 \%$ (Fig. 7).

Many DOMS studies conduct a subjective pain evaluation in conjunction with the collection of other data. ${ }^{5-7,10,23,26,45,46}$

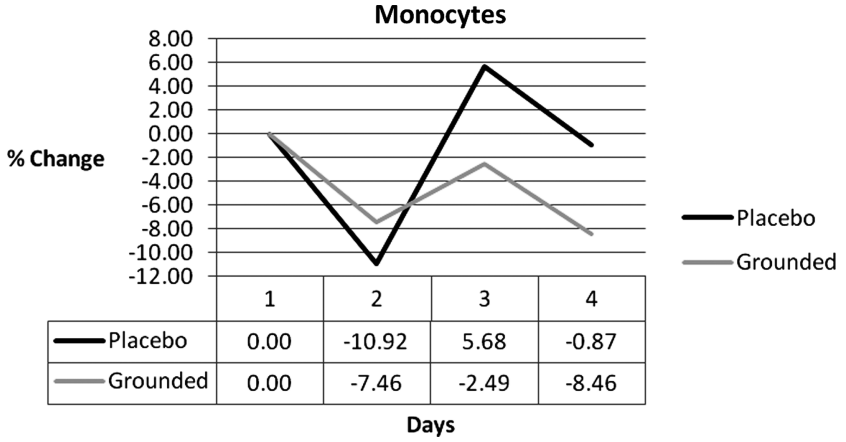

FIG. 4. Monocyte differences. 


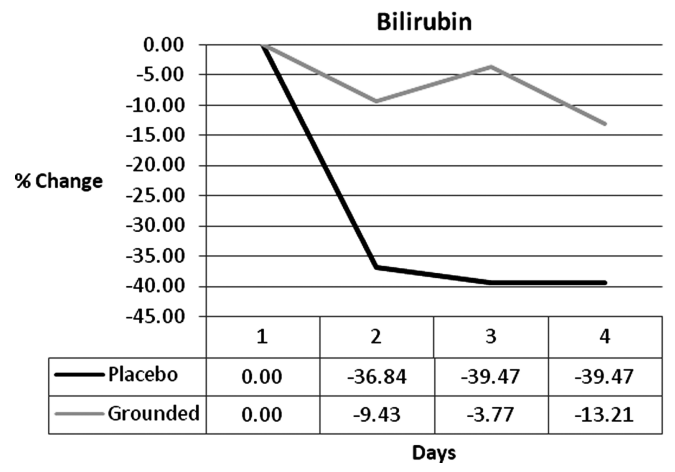

FIG. 5. Bilirubin differences.

In this study, a visual analogue pain scale ${ }^{5,7,10}$ was used to determine the subjective feeling of pain. Figure 8 shows the results. UNG had a higher perception of pain on each of the post-test days: $86 \%, 83 \%$, and $86 \%$. Some studies $5,10,30,47$ correlate subjective scales with objective pain data. In this study, a blood pressure cuff was applied to the right gastrocnemius. It was slowly inflated until the subject asked the investigator to stop inflating the cuff due to acute discomfort. The GRD group could tolerate a higher pressure (Fig. 9). The percent differences were $26 \%, 29 \%$, and $45 \%$. The results of the blood pressure cuff reinforce the subjective perception of pain.

Two other markers showed large differences between groups: glycerolphosphorylcholine (GPC) and phosphorylcholine (PC). These were determined by MRS and differences for GPC were $41 \%, 42 \%$, and $68 \%$. The differences for PC were $25 \%, 66 \%$, and $27 \%$. GPC is a potent choline donor. It can increase acetylcholine levels in motor units, ${ }^{48,49}$ is essential in phospholipids, a major component of all biological membranes, ${ }^{50}$ and is important in the release of human growth hormone. $^{51,52}$ Infante $^{53}$ showed that GPC aided sarcoplasmic $\mathrm{Ca}^{2+}$ transport, and Suchy et al. ${ }^{54}$ showed that cognitive degeneration was delayed with GPC supplementation. It was also shown that PC immunization reduces foam cells, which are products of inflammation. ${ }^{55}$

\section{Conclusions}

The purpose of the study was to determine whether certain markers could differentiate between GRD and UNG subjects who had experienced DOMS and grounding or

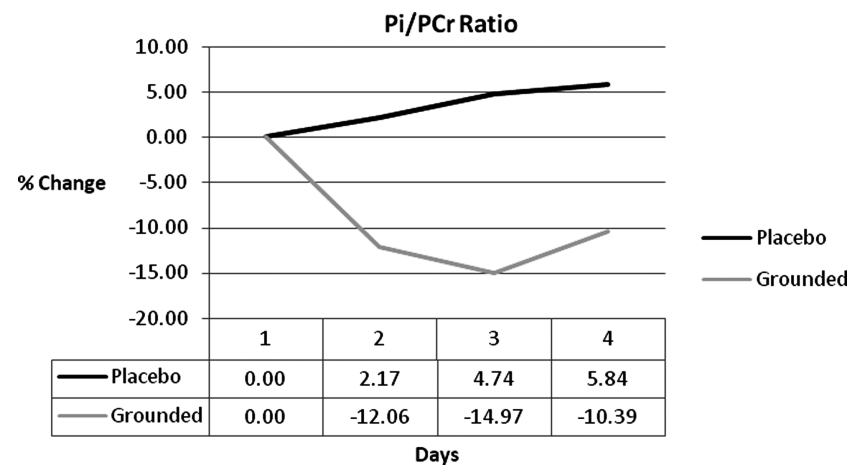

FIG. 7. Inorganic phosphate/phosphocreatine ratios (Pi/ $\mathrm{PCr}$ ) ratio differences.

sham-grounding. Forty-eight (48) markers were measured. In 30 of these markers, a consistent pattern emerged; over the 3-day testing period, one or the other group was always above or below the other group. Of 144 data points, 52 (36.1\%) showed differences of $10 \%$ or greater and $30(20.8 \%)$ showed differences of $20 \%$ or greater. White blood cells, neutrophils, lymphocytes, bilirubin, creatine kinase, $\mathrm{Pi} / \mathrm{PCr}$ ratios, GPC, PC and both a subjective and objective pain measurement had a strong, positive relationship with the grounded subjects. Grounding appears to be the first intervention with the potential to reduce the time of recovery and improve muscle function from DOMS. These findings suggest that grounding has enough of an effect on DOMS that a larger study is warranted.

\section{Acknowledgments}

The authors wish to acknowledge the professional assistance of Legacy Laboratories in Eugene, OR, the Lewis Center for Neuroimaging at the University of Oregon under the direction of Dr. Scott Frey, and the staff and management of the New Oregon Motel. The authors are grateful for the advice and guidance in MRS of Dr. Kevin McCully from the University of Georgia. Financial support for this project was provided by Earth FX Inc., Palm Springs, CA.

\section{Disclosure Statement}

R. (Dick) Brown worked as an independent contractor for this pilot study and has no financial interest in the company.

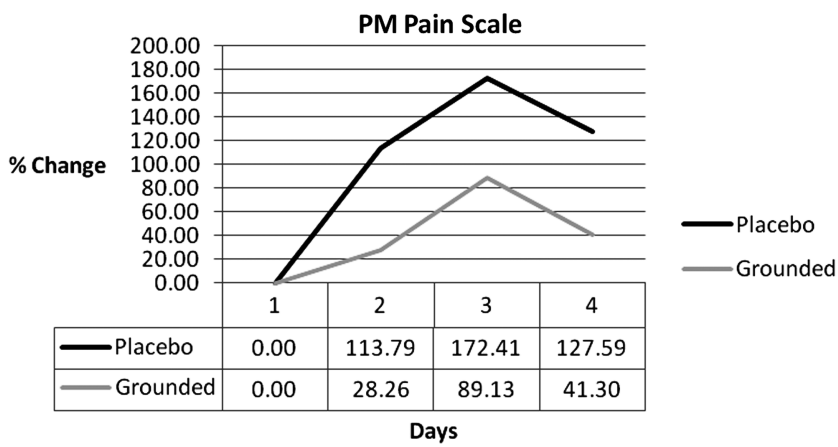

FIG. 8. PM pain scale. Visual analogue pain scale differences.

FIG. 6. Creatine kinase differences. 


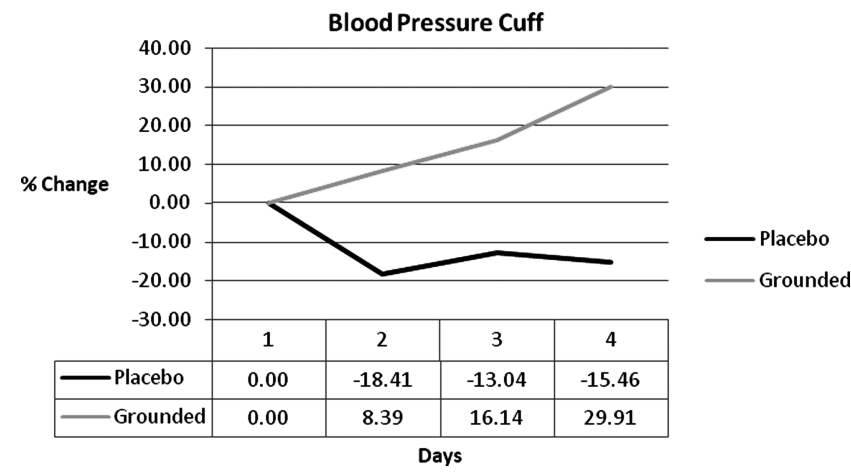

FIG. 9. Blood pressure cuff differences.

G. Chevalier has worked as an independent contractor for Earth FX since 2007 and owns a very small percentage of shares in the company. M. Hill worked as a graduate assistant for this pilot study and has no financial interest in the company.

\section{References}

1. Ghaly M, Teplitz D. The biological effects of grounding the human body during sleep, as measured by cortisol levels and subjective reporting of sleep, pain, and stress. J Altern Complement Med 2004;10:767-776.

2. Chevalier G, Mori K, Oschman JL. The effect of earthing (grounding) on human physiology. Eur Biol Bioelectromagn 2007;1:600-621.

3. Chevalier G. Changes in pulse rate, respiratory rate, blood oxygenation, perfusion index, skin conductance and their variability induced during and after grounding human subjects for forty minutes. J Altern Complement Med 2010;1:81-87.

4. Oschman JL. Can electrons act as antioxidants? A review and commentary. J Altern Complement Med 2007;13:955967.

5. Bobbert MF, Hollander AP, Hulling PA. Factors in delayed onset muscular soreness of man. Med Sci Sports Exerc 1986;18:75-81.

6. Tartibian B, Maleki BH, Abbasi A. The effects of ingestion of omega-3 fatty acids on perceived pain and external symptoms of delayed onset muscle soreness in untrained men. Clin J Sport Med 2009;19:115-119.

7. Vaile J, Halson S, Gill N, Dawson B. Effect of hydrotherapy on the signs and symptoms of delayed onset muscle soreness. Eur J Appl Physiol 2008;102:447-455.

8. Zainuddin Z, Newton M, Sacco P, Nosaka K. Effects of massage on delayed-onset muscle soreness, swelling, and recovery of muscle function. J Athl Train 2005;40:174-180.

9. Sayers SP, Dannecker EA. How to prevent delayed onset muscle soreness (DOMS) after eccentric exercise. Int Sport Med J 2004;5:84-97.

10. Hübscher M, Vogt L, Bernhörster M, et al. Effects of acupuncture on symptoms and muscle function in delayedonset muscle soreness. J Altern Complement Med 2008;14: 1011-1016.

11. Dutto DJ, Braun WA. DOMS-associated changes in ankle and knee joint dynamics during running. Med Sci Sports Exerc 2004;36:560-566.

12. Butterfield TA, Best TM, Merrick MA. The dual roles of neutrophils and macrophages in inflammation: A critical balance between tissue damage and repair. J Athl Train 2006;41:457-465.

13. Takmakidis SP, Kokkinidis EA, Similios I, Douda H. The effects of ibuprofen on delayed onset muscle soreness and muscular performance after eccentric exercise. J Strength Cond Res 2003;17:53-59.

14. Close GL, Ashton T, Cable T, et al. Eccentric exercise, isokinetic muscle torque and delayed onset muscle soreness: The role of reactive oxygen species. Eur J Appl Physiol 2004;91:615-621.

15. MacIntyre DL, Reid WD, Lyster DM, et al. Presence of WBC, decreased strength, and delayed soreness in muscle after eccentric exercise. J Appl Physiol 1996;80:1006-1013.

16. Franklin ME, Currier D, Franklin RC. The effect of one session of muscle soreness inducing weight lifting exercise on WBC count, serum creatine kinase, and plasma volume. J Orthop Sports Phys Ther 1991;13:316-321.

17. Peake J, Nosaka K, Suzuki K. Characterization of inflammatory responses to eccentric exercise in humans. Exerc Immunol Rev 2005;11:64-85.

18. Smith LL, Bond JA, Holbert D, et al. Differential white cell count after two bouts of downhill running. Int J Sports Med 1998;19:432-437.

19. MacIntyre DL, Reid WD, McKenzie DC. Delayed muscle soreness: The inflammatory response to muscle injury and its clinical implications. Sports Med 1995;20:24-40.

20. Smith LL. Cytokine hypothesis of overtraining: A physiological adaptation to excessive stress? Med Sci Sports Exerc 2000;32:317-331.

21. Ascensao A, Rebello A, Oliveira E, et al. Biochemical impact of a soccer match: Analysis of oxidative stress and muscle damage throughout recovery. Clin Biochem 2008;41:841851.

22. Smith LL, McCammon M, Smith S, et al. White blood cell response to uphill walking and downhill jogging at similar metabolic loads. Eur J Appl Physiol 1989;58:833-837.

23. Broadbent $S$, Rousseau JJ, Thorp RM, et al. Vibration therapy reduces plasma IL-6 and muscle soreness after downhill running. Br J Sports Med 2008;Sept 23:e-pub ahead of print.

24. Gleeson M, Almey J, Brooks S, et al. Haematological and acute phase responses associated with delayed-onset muscle soreness. Eur J Appl Physiol Occup Physiol 1995;71:137142.

25. Tidball JG. Inflammatory processes in muscle injury and repair. Am J Physiol Regul Integr Comp Physiol 2005;288: R345-R353.

26. Zhang J, Clement D, Taunton J. The efficacy of Farabloc, an electromagnetic shield, in attenuating delayed onset muscle soreness. Clin J Sports Med 2000;10:15-21.

27. Malm $C$, Nyberg $P$, Engstrom $M$, et al. Immunological changes in human skeletal muscle and blood after eccentric exercise and multiple biopsies. J Physiol 2000;529(pt 1):243262.

28. Toumi H, Best TM. The inflammatory response: Friend or enemy for muscle injury? Br J Sports Med 2003;37:284-286.

29. Kostuyk VA, Potapovich AI. Mechanisms of the suppression of free radical overproduction by antioxidants. Front Biosci 2009;E1:179-188.

30. Close GL, Ashton T, McArdle A, MacLaren DP. The emerging role of free radicals in delayed onset muscle soreness and contraction-induced muscle injury. Comp Biochem Physiol 2005;142:257-266.

31. Close GL, Ashton T, Cable T, et al. Effects of dietary carbohydrate on delayed onset muscle soreness and reactive 
oxygen species after contraction induced muscle damage. $\mathrm{Br}$ J Sports Med 2005;39:948-953.

32. Best TM, Hunter KD. Muscle injury and repair. Phys Med Rehabil Clin North Am 2000;11:251-266.

33. Stocker R. Antioxidant activities of bile pigments. Antioxid Redox Signal 2004;6:841-849.

34. Paschalis V, Nikoladis MG, Fatouros IG, et al. Uniform and prolonged changes in blood oxidative stress after muscle damaging exercise. In Vivo 2007;21:877-883.

35. Nikoladis MG, Paschalis V, Giakas G, et al. Decreased blood oxidative stress after repeated muscle damaging exercise. Med Sci Sports Exerc 2007;21:1080-1089.

36. Florczk UM, Jozkowicz A, Dulak J. Biliverdin reductase: New features of an old enzyme and its potential therapeutic significance. Pharmacol Rep 2008:60:38-48.

37. Sedlak TW, Salehb M, Higginson DS, et al. Bilirubin and glutathione have complementary antioxidant and cytoprotective roles. Proc Natl Acad Sci USA 2009;106:51715176.

38. Hirose L, Nosaka K, Newton M, et al. Changes in inflammatory mediators following eccentric exercise of the elbow flexors. Exerc Immunol Rev 2004;10:75-90.

39. Hartmann U, Mester J. Training and overtraining markers in selected sport events. Med Sci Sports Exerc 2000;32:209-215.

40. McCully KK, Posner J. Measuring exercise-induced adaptations and injury with magnetic resonance spectroscopy. Int J Sports Med 1992;13(suppl 1):S147-S149.

41. McCully KK, Shellock FG, Bank WJ, Posner JD. The use of nuclear magnetic resonance to evaluate muscle injury. Med Sci Sports Exerc 1992;24:537-542.

42. Zehnder M, Muelli M, Buchli R, et al. Further glycogen decrease during early recovery after eccentric exercise despite a high carbohydrate intake. Eur J Nutr 2004;43:148-159.

43. McCully KK, Argov Z, Boden BP, et al. Detection of muscle injury in humans with 31-P magnetic resonance spectroscopy. Muscle Nerve 1988;11:212-216.

44. Prabhakar G, Vona-Davis L, Murray D, et al. Phosphocreatine restores high-energy phosphates in ischemic myocardium: Implication for off-pump cardiac revascularization. J Am Coll Surg 2003;197:786-791.

45. Sellwood KL, Brukner P, Williams D, et al. Ice-water immersion and delayed onset muscle soreness: A randomized controlled trial. Br J Sports Med 2007;41:392-397.
46. Staples JR, Clement DB, Taunton JE, McKenzie DC. Effects of hyperbaric oxygen on a human model of injury. Am J Sports Med 1999;27:600-605.

47. Bailey DM, Davies B, Davison G, Young IS. Free radical damage at high altitude: Isolating the source and implications for the pathophysiology of acute mountain sickness. Newslett Int Soc Mountain Med 2000;10:3-13.

48. Novak M, Hameed N, Buist R, Blackburn BJ. Metabolites of alveolar echinococcus as determined by [31P] and [1H]nuclear magnetic resonance spectroscopy. Parasitol Res 1992; 78:665-670.

49. Drago F, D'Agata V, Guido G. Effects of $L$ - $\alpha$-glycerylphosphorylcholine on drug-induced behavioral alterations in rats. Dementia 1992;3:7-9.

50. Janko K, Benz R. Properties of lipid bilayer membranes from lipids containing phytanic acid. Biochim Biophys Acta 1977;470:8-16.

51. Ceda GP, Ceresini G, Denti L, et al. Alpha-glycerylphosphorylcholine administration increases the GH responses to GHRH of young and elderly subjects. Horm Metab Res 1992;24:119-121.

52. Ceda GP, et al. GH responses to GHRH in old subjects and in patients with senile dementia of the Alzheimer's type: The effects of an acetylcholine precursor. Adv Biosci 1993;87: 425-428.

53. Infante JP. Impaired biosynthesis of highly unsaturated phosphatidylcholine: A hypothesis on the molecular etiology of some muscular dystrophies. J Theor Biol 1985;116:65-88.

54. Suchy J, Chan A, Shea TB. Dietary supplementation with a combination of alpha-lipoic acid, acetyl-L-carnitine, glycerophosphocholine, docosahexaenoic acid, and phosphatidylserine reduces oxidative damage to murine brain and improves cognitive performance. Nutr Res 2009;29:70-74.

55. Caligiuri G, Khallou-Laschet J, Vandaele M, et al. Phosphorylcholine-targeting immunization reduces atherosclerosis. J Am Coll Cardiol 2007;50:540-546.

Address correspondence to: Gaétan Chevalier, Ph.D.

924 Encinitas Boulevard \#86 Encinitas, CA 92024

E-mail: dlbogc@sbcglobal.net 
